\title{
BMJ Health \& Care Informatics \\ Effectiveness of patient education in acute stroke: a comparison between a customised computer system and a pictorial information booklet
}

Yin Man Chu, ${ }^{1}$ Kup Sze Choi ${ }^{2}$

To cite: Chu YM, Choi KS. Effectiveness of patient education in acute stroke: a comparison between a customised computer system and a pictorial information booklet. BMJ Health Care Inform 2020;27:e100144. doi:10.1136/ bmjhci-2020-100144

Received 02 March 2020 Revised 07 July 2020 Accepted 08 July 2020
Check for updates

(C) Author(s) (or their employer(s)) 2020. Re-use permitted under CC BY-NC. No commercial re-use. See rights and permissions. Published by BMJ.

${ }^{1}$ Department of Medicine, Tseung Kwan 0 Hospital, Tseung Kwan 0, Hong Kong

${ }^{2}$ School of Nursing, Hong Kong Polytechnic University, Kowloon, Hong Kong

Correspondence to

Yin Man Chu;

cymz02@ha.org.hk

\begin{abstract}
Background Patients who develop acute stroke are at high risk for deterioration in the first 48-72 hours after admission. An effective educational intervention is needed. Objective This study aimed to examine the applicability of the customised interactive computer education system (CICS) in patients who had a stroke in the early acute phase in order to determine the efficacy of the education system in (1) information satisfaction and (2) physiological related management compliance.
\end{abstract}

Methods The prospective non-blinded randomised controlled study was conducted in an acute stroke unit of a local hospital in Hong Kong from March to August 2019. Chinese participants were selected if they were at least 18 years of age, experienced a minor stroke within 3 days. The exclusion criteria were communication problem and comorbidity with another acute disease. On the first day of admission, participants were allocated to the CICS and booklet groups, with each group comprising 50 participants. On the third day, the primary outcome, Modified Information Satisfaction Questionnaire for Acute Stroke (MISQ-S), was assessed. Results There was a significant difference in 'the need to improve information measures' of the MISQ-S $(p=0.04)$ between the CICS and booklet groups. The management compliance of these two groups did not have difference, but the CICS group had better clinical outcome, though not significant ( $p=0.387$ ).

Conclusion Patient education was needed and feasible in the early acute phase, and the CICS was more efficacious than the booklet. The positive results provided insights into and give a direction to the use of information technology in patient education.

\section{INTRODUCTION}

It has been estimated that 15 million people experience a stroke annually. ${ }^{12}$ Based on epidemiological studies, about $85 \%$ of patients who had a stroke have an ischaemic stroke, which involves blockage of a cerebral vessel with neurological deficit. ${ }^{3}$ Approximately one-third of patients who had a stroke deteriorate after admission ${ }^{4}$ because the cerebral blood flow further decreases, preventing neurons from surviving. However, patients' symptoms can reverse spontaneously and quickly, ${ }^{5}$ in which case it is diagnosed as a transient ischaemic attack.

Many patients have misconception of active movement that can promote recovery. Patients' misconception of recovery by intensive movement could lead to insufficient cerebral perfusion, matched with the phenomenon of neurological deterioration. ${ }^{67}$ However, till now, most studies have focused on poststroke education after patients are stabilised or on long-term management. ${ }^{8}$ Six electronic booklets by relevant authorities were found on the internet, and one hardcopy booklet was collected from a local hospital. Only three booklets covered information on the acute phase and no recommendation for patient activities was available. Therefore, an effective educational intervention for patients who had a stroke on their admission is required.

Dehydration is common in patients who had a stroke, especially in elderly patients and women on admission ${ }^{10-12}$ Dehydration can reduce the cerebral blood flow to the potentially vulnerable brain tissue around the infarct core, which is termed the penumbra. ${ }^{13}$ Dehydrated patients were significantly more likely to be dependent or die on hospital discharge than hydrated patients. ${ }^{14}$ Blood flow to the brain can be reflected by blood pressure. High blood pressure was allowed as $220 \mathrm{~mm} \mathrm{Hg}$ in the acute phase. ${ }^{15} 16$ Cerebral blood flow velocity is also a surrogate of brain perfusion. ${ }^{17}$ Studies that used transcranial Doppler ultrasonography to evaluate cerebral perfusion found that ahead position greater than $30^{\circ}$ was deleterious to the brain during acute stroke. ${ }^{18-20}$ Studies showed that very early mobilisation was not associated with a good outcome at 90 days or even an increased mortality. ${ }^{21}{ }^{22}$ Many studies have not explained the physiological relationship of mobilisation or upright positions and the confounding effects.

A customised interactive computer education system (CICS) explaining the physiological 


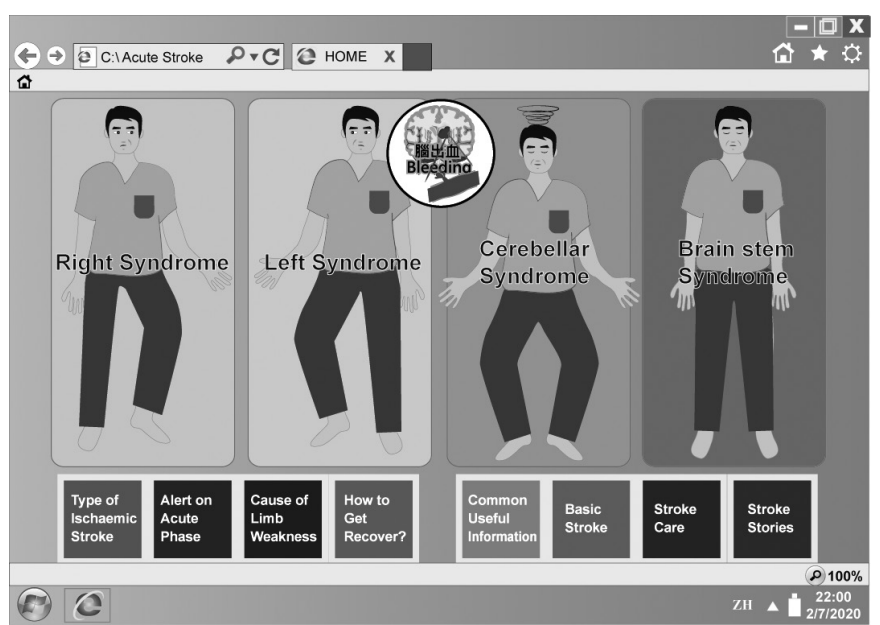

Figure 1 Home page with pictures for different symptoms according to symptoms. Patient can clip on pictures and icons, and go to the related information page (English translation).

changes had been developed for patient education during the acute stroke phase. A 10-inch tablet computer with multimedia functions and touch screen display screen was used as the tool for this. Information was provided in written, graphic and audio format, with some animations. Samples of the screen display are shown in figures 1-3.

This study aimed to examine the applicability of the CISC in patients who had a stroke in the early acute phase in order to determine the efficacy of the education system in (1) information satisfaction and (2) physiological related management compliance.

\section{METHODS}

\section{Research design}

A prospective non-blinded randomised controlled study design was used (figure 4). Random sampling was used, and eligible patients were randomly assigned to the intervention

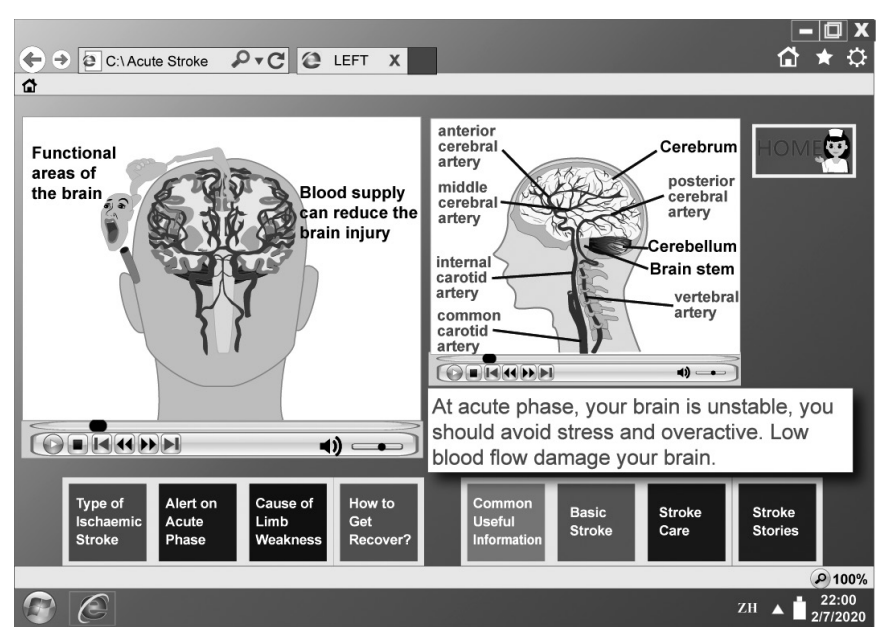

Figure 2 Web page of stroke symptoms using animations illustrates the blood clogging and affecting functional area (left). Structure of the brain in the lateral view (right; English translation).

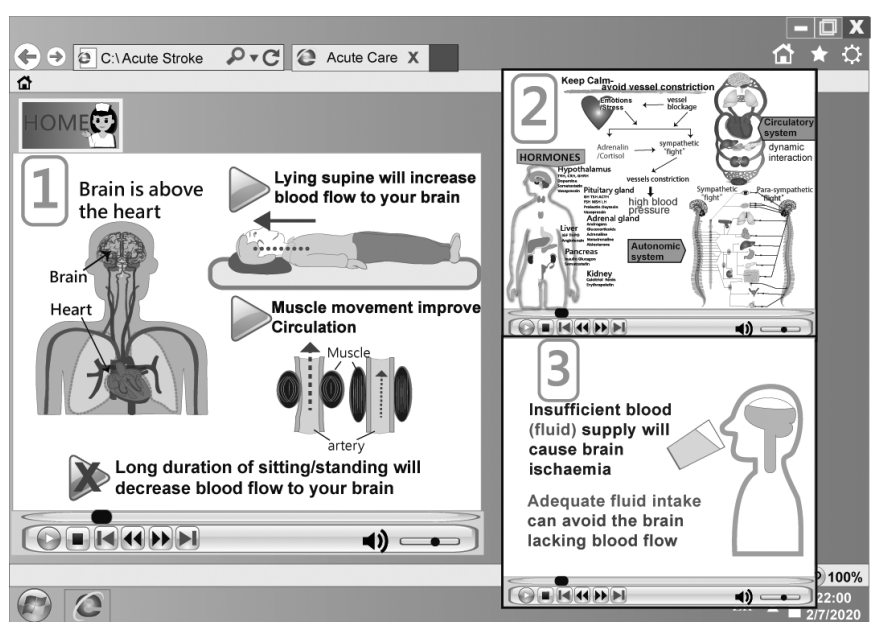

Figure 3 Web page with title on 'Alerts on acute stroke phase', using animations to explain the physiological change with appropriate interventions (English translation).

group and control group. A random sequence was generated by a computer program (research randomiser, randomizer. org). The intervention group (CICS) was offered the CICS on the day of admission, whereas the control (booklet) group was provided with a pictorial information booklet with similar content on the day of admission. No standard group was used as the comparison group because routine patient education is barely consistent and provided by different healthcare professionals. A pilot study of 20 participants was conducted before the main study was performed to determine the feasibility of the study and calculate the sample size for the main study.

\section{Study setting, sample, sampling and sample size}

The research study was carried out in an acute stroke unit (ASU) of a public acute care hospital in Hong Kong, China, from March to August 2019. The inclusion criteria were (1) age $\geq 18$ years, (2) admission from accident and emergency,

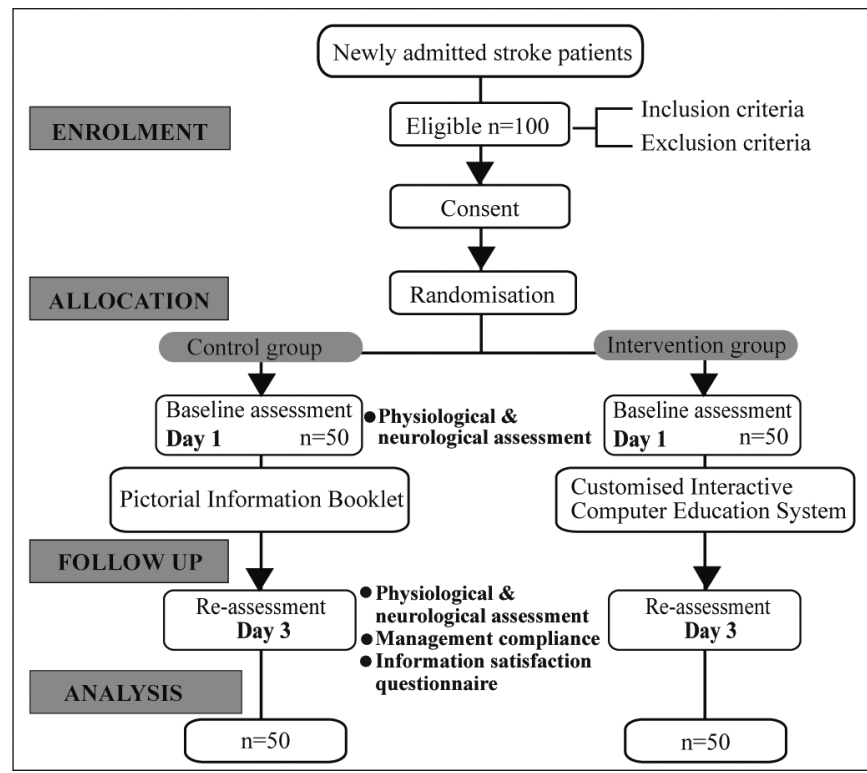

Figure 4 Flow of the study. 
(3) diagnosis of acute ischaemic stroke or equivalent, (4) onset of a stroke symptom within 3 days, (5) minor stroke on admission, (6) first hospital admission for acute ischaemic stroke and (7) receipt of standard treatment for stroke. The exclusion criteria were (1) communication problem, (2) mental incapacity, rating below $21 / 30$ according to the Chinese Mini-Mental State Examination or (3) comorbidity with another acute disease, such as infection, respiratory diseases, cardiac diseases or renal diseases.

The pilot study indicated that the effect size of the Modified Information Satisfaction Questionnaire for Acute Stroke (MISQ-S) was 05. With a power of 0.8 and significance of 0.05 , a sample size of 50 participants was required for each group. ${ }^{23}$ As the study period was conducted within a short time and the study included patients with relatively stable health conditions who were receiving treatment, no attrition rate was assumed.

\section{Intervention group}

After randomisation, participants allocated to the intervention group were offered a tablet computer with the CICS at their bedside until discharge. The researcher introduced the participants to their specific condition and provided related information. The researcher advised the patient on how to further explore information, and the participant could repeatedly retrieve the information.

\section{Control group}

A pictorial information booklet was developed to compare with the CICS and used in the control group. The booklet contained key information like the CICS, including content on different categories of stroke syndrome and information on acute management and rehabilitation. The booklet was given to participants within the first 24 hours after admission to ASU. Additional information in the stroke health education booklet, which was also available in the ASU, was provided as a supplement. The researcher explained the content of the booklet to the participant and left the booklet for the participant.

\section{Data collection}

Participants' demographic data and medical history were obtained from their medical records. The progression of stroke conditions, such as vital signs, brain CT findings and neurological observations, was determined. The primary outcome was information satisfaction, which was measured using the MISQ-S, which was adopted from the Information Satisfaction Questionnaire by Davies, Kinman, Thomas and Bailey. ${ }^{24}$ The secondary outcomes were physiological related management compliance and change in the National Institute of Health and Stroke Scale (NIHSS) score. Physiological related management

Table 1 Baseline information of the participants

\begin{tabular}{|c|c|c|c|c|}
\hline & Total & CICS & Booklet & $P$ value \\
\hline Male, n (\%) & $72(72)$ & $36(72)$ & $36(72)$ & $1.0^{*}$ \\
\hline Female, n (\%) & $28(28)$ & $14(28)$ & $14(28)$ & \\
\hline Age, mean (SD) & $62.92(10.8)$ & $63.02(9.97)$ & $62.94(11.70)$ & $0.997 \dagger$ \\
\hline CMMSE: mean (SD) & $22.85(2.9)$ & $22.84(2.9)$ & $22.86(2.9)$ & $0.63 \dagger$ \\
\hline Diagnosis, n (\%) & & & & $0.843^{*}$ \\
\hline Right AIS & $34(34)$ & $17(34)$ & $17(34)$ & \\
\hline Right acute brain stroke & $17(17)$ & $8(16)$ & $9(9)$ & \\
\hline Left AIS & $33(33)$ & $18(36)$ & $15(30)$ & \\
\hline Left acute brain stroke & $15(15)$ & 7 (14) & $8(16)$ & \\
\hline Cerebellar & $1(1)$ & $0(0)$ & $1(2)$ & \\
\hline CT finding, $\mathrm{n}(\%)$ & & & & $0.951^{*}$ \\
\hline Lacunar & 45 & 25 & 20 & \\
\hline Large vessel arthrosclerosis & 13 & 20 & 22 & \\
\hline No abnormal finding & 42 & 5 & 8 & \\
\hline \multicolumn{5}{|l|}{ NIHSS, mean (SD) } \\
\hline First day & $2.28(1.87)$ & $2.34(1.83)$ & $2.22(1.93)$ & $0.65 \dagger$ \\
\hline \multicolumn{5}{|l|}{ Systolic BP, mean (SD) } \\
\hline First day & $158.15(29.13)$ & $159.16(30.2)$ & $157.14(28.26)$ & $0.69 \dagger$ \\
\hline \multicolumn{5}{|l|}{ Diastolic BP, mean (SD) } \\
\hline First day & $91.87(18.73)$ & $92.36(20.69)$ & $91.38(16.73)$ & $0.92 \dagger$ \\
\hline
\end{tabular}

*Fisher's exact test.

†Mann-Whitney U test.

AIS, acute ischeamic stroke; BP, blood pressure; CICS, customised interactive computer education system; CMMSE, Chinese Mini-Mental State Examination; NIHSS, National Institute of Health and Stroke Scale. 
Table 2 Comparison of information satisfaction between customised interactive computer education system (CICS) group and booklet group

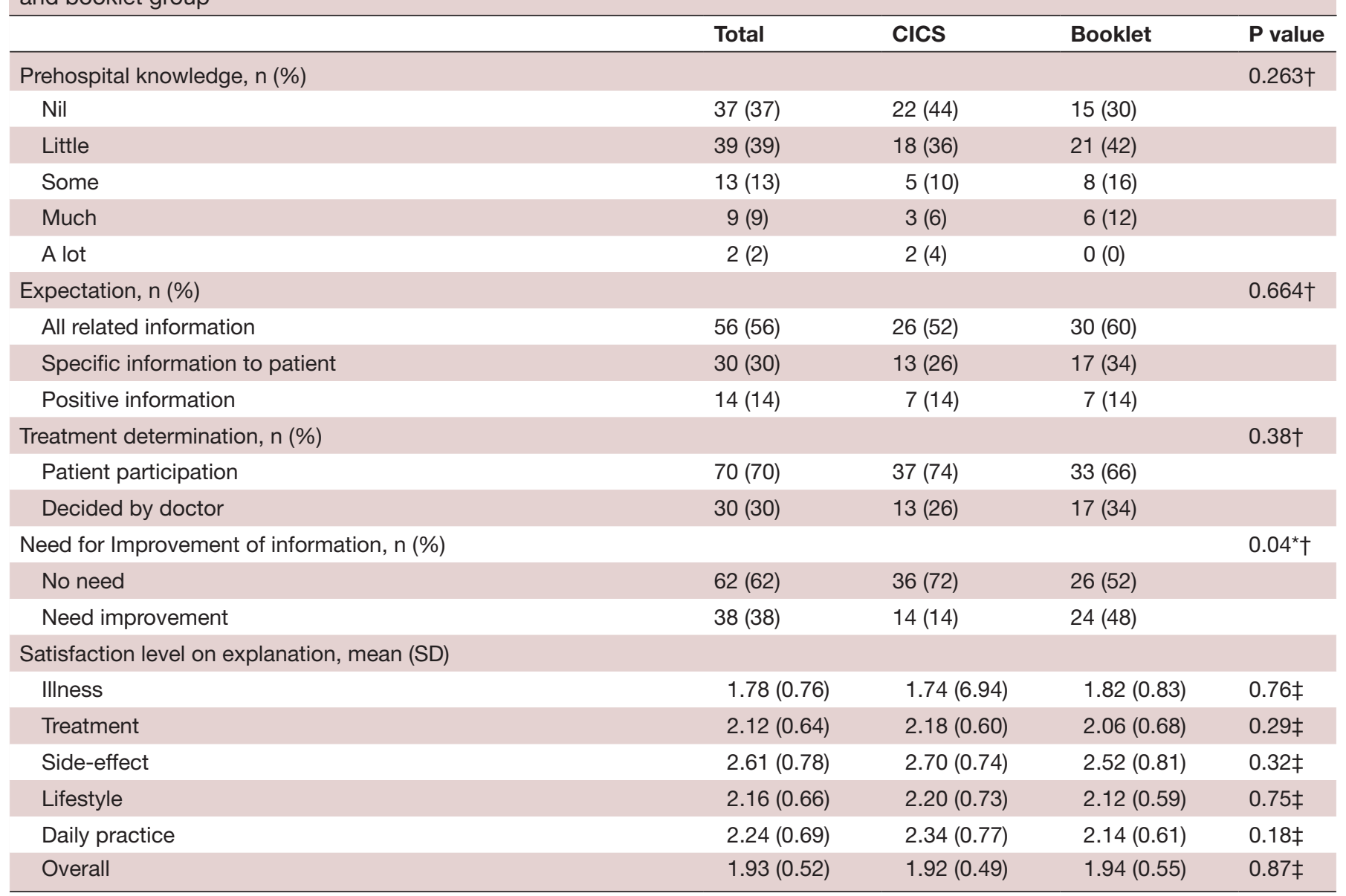

${ }^{*} \mathrm{P}<0.05$

†Fisher's exact test.

$\ddagger$ Mann-Whitney U test.

compliance included positioning and mobilisation, sufficient fluid intake and avoidance of psychological stress, which were self-reported by participants. The NIHSS is a well-established, standardised measurement of the severity of stroke internationally.

\section{Quality control}

Both groups were asked if they had any issue with the randomly selected education measures after they entered the study. Within the study period, they were also reminded to use the CICS or pictorial information booklet. Participants were invited to ask question(s) if they had encountered difficulty with the selected patient education measures. In order to prevent bias, the presence of different group participants in the same study period was avoided. This was done by either different group sequence or keeping the two different groups of participants in different locations. The participants were also checked by a researcher for possible bias.

Participants were invited to participant on a voluntary basis and provided written informed consent. They were ensured of their rights to refuse and withdraw from the study at any time. Participants were also assured that there would be no consequence for non-participation. Limited identifying information was used, and data were kept anonymous after completion of data collection. All personal data were kept confidential in a designated locked cabinet, and no USB drive was used for the storage of personal data.

\section{Statistical analysis}

Data analysis using SPSS V.25, non-parametric tests were computed with $\mathrm{p}$ value $<0.5$, two-tailed test. Descriptive data will be presented to illustrate the baseline and outcomes of the intervention. The nominal data of MISQ-S and management compliance were inferenced using Fisher's exact test. The ordinal data of MIPQ-S and change of NIHSS were analysed with the Mann-Whitney U test.

\section{RESULTS}

The study unit admitted around 350 patients suffered from stroke in different degree of severity in every year. During the study period, 100 patients had fulfilled the study criteria and agreed to participated the study. Table 1 illustrates the baseline information of the study groups. There was no significant difference in baseline 
Table 3 Comparison of management compliance between customised interactive computer education system (CICS) group and booklet group

\begin{tabular}{|c|c|c|c|c|}
\hline & Total & CICS & Booklet & $P$ value \\
\hline \multicolumn{5}{|c|}{ Management compliance $\mathrm{n}(\%)$} \\
\hline Position/mobilisation & $100(100)$ & $50(100)$ & $50(100)$ & $1.0^{*}$ \\
\hline Sufficient fluid intake & $100(100)$ & $50(100)$ & $50(100)$ & $1.0^{*}$ \\
\hline Stress avoidance & $83(83)$ & $40(80)$ & $37(74)$ & $0.476^{\star}$ \\
\hline
\end{tabular}

*Fisher's exact test.

data between the groups. The pathological positions on the right and left sides were similar. Both groups also had a similar severity of stroke, with an average NIHSS score of $2 \pm 1.87$, and blood pressure was generally high (>140 mm Hg).

According to the MISQ-S, 76\% of participants did not have or had little knowledge on stroke (table 2). Five to six per cent of participants replied that they had much knowledge on stroke. There was no difference in background knowledge on stroke before admission between the groups. With regard to their expectation of information, more than $50 \%$ of participants expected to receive more information on stroke. More than $25 \%$ of participants focused on their type of stroke, and $14 \%$ of participants preferred positive information about their conditions. With regard to treatment decision-making, $30 \%$ of participants preferred the doctor to make the decision for them, while $70 \%$ of participants preferred to be involved in their treatment and care. A significant number of participants believed that the booklet needed improvement $(\mathrm{p}=0.04)$.

Participants were advised about how their position and mobilisation affect brain circulation, the need for sufficient fluid intake and impact of undue stress. Participants were asked whether they had followed physiological related management advice on day 3 after admission. Both groups fully complied with body positioning, mobilisation and fluid intake (table 3). Ten participants in the intervention group replied that they did not avoid stress, and 13 participants in the control group rated did not avoid stress.

Refer to table 4, the mean NIHSS score from the first day of admission and day 3 decreased in the intervention group, indicating improvement, while it increased in the control group, indicating worsening. In the intervention group, five participants deteriorated on day 3 , and in the booklet group, three participants improved and three participants deteriorated. There was no significant difference in the NIHSS score between the groups.

\section{DISCUSSION}

\section{Main findings}

This study found that $70 \%$ of participants would like to participate and make decisions about their healthcare, whereas $30 \%$ of participants preferred that their doctor
Table 4 Comparison of National Institute of Health and Stroke Scale (NIHSS) change between customised interactive computer education system (CICS) group and booklet group

\begin{tabular}{lllll}
\hline & Total & CICS & Booklet & P value \\
\hline NIHSS & & & & \\
\hline $\begin{array}{l}\text { First day: } \\
\text { mean (SD) }\end{array}$ & $2.28(1.87)$ & $2.34(1.83)$ & $2.22(1.93)$ & $0.75^{\star}$ \\
$\begin{array}{l}\text { Day 3: mean } \\
\text { (SD) }\end{array}$ & $2.07(2.35)$ & $1.72(1.72)$ & $2.42(2.82)$ & $0.44^{*}$ \\
\hline NIHSS change first day, D3, $\mathrm{n}(\%)$ & & & \\
$\begin{array}{l}\text { No change } \\
\text { No of }\end{array}$ & $89(89)$ & $45(90)$ & $44(88)$ & $0.387^{*}$ \\
$\begin{array}{l}\text { improvement } \\
\text { No of } \\
\text { deterioration }\end{array}$ & $4(4)$ & $4(8)$ & $3(6)$ & \\
\hline
\end{tabular}

*Fisher's exact test.

make the treatment decisions. Therefore, participants would like to take an active role in their daily care or activities during hospitalisation. In addition, the CICS met the seven principles for improving patient education. ${ }^{25}$ First, the CICS was easy to access and use, and it did not require much working memory. Second, the user could operate the device at his/her own pace. Third, tailor-made information decreased extraneous cognitive load (irrelevant information). Fourth, the CICS used words and graphics for better illustration of concepts. Fifth, the CICS used words and graphics at the same time to improve understanding. Sixth, the CICS used visual methods, such as animation, to present physiology. Seventh, materials were integrated to produce an effective presentation. According to Friedman $e t a l,{ }^{26}$ tailored information using computer technology was seen to be superior than other teaching measures. The CICS has the feature of illustrating pathophysiology using a simple animation so non-professionals can easily understand and memorise the information. It also demonstrated how blood flow enters the brain and how the nerve impulse is transmitted, which is fundamental for restoring the blood flow or brain perfusion.

\section{Is spontaneous recovery after stroke possible?}

Although this study did not find a significant difference in the improvement of severity of stroke between the groups, the data of both groups showed that $7 \%$ of participants showed improvement in terms of reduction of the NIHSS score by at least four points. The early acute phase is crucial for recovery. As explained by Cassidy and Cramer, ${ }^{27}$ few hours and few days belong to the first two recovery epochs among three epochs. In these epochs, discrete physiological and pathological events are conducive to changes in the brain. In this study, $4 \%$ of participants had early neurological deterioration. A review ${ }^{28}$ showed that early neurological deterioration occurred in $13.3 \%-31.6 \%$ of cases, which included different severities of stroke. In a Japanese study of 543 patients with 
minor stroke, $6.8 \%$ of them had clinical worsening within 7 days. ${ }^{29}$ This percentage might not be comparable to our study finding, but it highlights that large vessel disease, high blood pressure, increased blood glucose level and symptoms of dizziness are predisposing factors of clinical worsening after stroke. In our study, $13 \%$ of patients had large vessel disease according to CT, although their symptoms were minor.

\section{Implications of this study}

Patient education in the early acute phase of stroke might not be a great concern from the perspective of the healthcare team. ${ }^{30}$ This study's findings indicated that education in the early phase is needed, feasible and evidence based. The use of computer technology in patient education can help illustrate how the body changes during stroke. A better understanding of stroke will improve patients' cognitive need and empower them to make healthy decisions. The CICS can offer preliminary information to patients' family that is specific to their needs. Even when family is consulted by a healthcare team, it is common for them to miss or misinterpret of information. ${ }^{31}$ The healthcare team can use the CICS to clearly present the information. Moreover, using evidence-based information in designing patient education is crucial for improving clinical outcomes. ${ }^{32}$ The web-based environment and tools can facilitate better patient education in caring process. $^{33}$

\section{Limitations}

Although this study was a randomised control trial, the results should be interpreted with caution, as there are several limitations. First, the study was conducted in one ASU of a local hospital, and this limited generalisation of the findings. Second, with regard to physiological related management compliance, the advice might not have been consistent, and the variable was a self-reporting result. Third, several confounding variables may also have affected the results, and each individual's comorbid condition may be different. In addition, patients could have had different communications and interactions with stroke team members, patients and visitors; this factor is uncontrollable and difficult to measure. Participants' mean age was 60 years, and most participants were men; therefore, this study's findings might not apply to older or younger and female patients. Lastly, this study did not evaluate patients' experience with using information technology, as the interface was simple. However, participants might have a different experience with using a smart device, and this could affect their use and the outcome. Some people might have an information technology phobia. Thus, further studies on this topic are recommended.

\section{CONCLUSION}

To date, previous studies have assessed the impact of patient position, early mobilisation and dehydration on stroke recovery. The findings of these studies indicated that patients' stroke outcome can improve or deteriorate, and patients can contribute to their own recovery. Additionally, inappropriate activities can be detrimental to stroke conditions. A CICS has been developed for patient education in the early acute phase of stroke, and our study demonstrated that patient education in the early acute phase is needed and feasible, especially with the support of the CISC. Nevertheless, there is a need to further develop the patient education system and study its efficacy in patients who had a stroke as well as in different areas of healthcare.

Acknowledgements The authors would like to thank the Stroke Team and Department of Medicine, Tseung Kwan 0 Hospital, for their great support in this study.

Contributors Conception and design of the study; data analysis; manuscript writing and revision: both authors. Recruitment of participants and data collection: YMC. Study supervision: KSC.

Funding The authors have not declared a specific grant for this research from any funding agency in the public, commercial or not-for-profit sectors.

Competing interests None declared.

Patient consent for publication Not required.

Ethics approval The study protocol was approved by the Human Subjects Ethics Subcommittee of the Hong Kong Polytechnic University (HSEARS20170511003) and Research Ethics Committee (Kowloon Central/Kowloon East) of the Hospital Authority (KC/KE-18-0303/ER-1) for ethical approval. Relevant guidelines were strictly followed.

Provenance and peer review Not commissioned; internally peer reviewed.

Data availability statement Data are available upon reasonable request. The data have been anonymised and available upon reasonable request and by the permission of Tseung Kwan Hospital.

Open access This is an open access article distributed in accordance with the Creative Commons Attribution Non Commercial (CC BY-NC 4.0) license, which permits others to distribute, remix, adapt, build upon this work non-commercially, and license their derivative works on different terms, provided the original work is properly cited, appropriate credit is given, any changes made indicated, and the use is non-commercial. See: http://creativecommons.org/licenses/by-nc/4.0/.

\section{REFERENCES}

1 Considine J, McGillivray B. An evidence-based practice approach to improving nursing care of acute stroke in an Australian emergency department. J Clin Nurs 2010;19:138-44.

2 Kulshreshtha A, Anderson LM, Goyal A, et al. Stroke in South Asia: a systematic review of epidemiologic literature from 1980 to 2010. Neuroepidemiology 2012;38:123-9.

3 Felberg RA, Naidech AM. The 5 Ps of acute ischemic stroke treatment: parenchyma, pipes, perfusion, penumbra, and prevention of complications. South Med J 2003;96:336-42.

4 Thanvi B, Treadwell S, Robinson T. Early neurological deterioration in acute ischaemic stroke: predictors, mechanisms and management. Postgrad Med J 2008;84:412-7.

5 Silvestrini M, Caltagirone C, Cupini LM, et al. Activation of healthy hemisphere in poststroke recovery. A transcranial Doppler study. Stroke 1993;24:1673-7.

6 Ju Y, Zhao X-Q, Wang C-X, et al. Neurological deterioration in the acute phase of minor ischemic stroke is an independent predictor of poor outcomes at 1 year: results from the China national stroke registry (CNSR). Chin Med J 2013;126:3411-6.

7 AVERT Trial Collaboration group. Efficacy and safety of very early mobilisation within $24 \mathrm{~h}$ of stroke onset (AVERT): a randomised controlled trial. Lancet 2015;386:46-55.

8 Hafsteinsdóttir TB, Vergunst M, Lindeman E, et al. Educational needs of patients with a stroke and their caregivers: a systematic review of the literature. Patient Educ Couns 2011;85:14-25.

9 van Veenendaal H, Grinspun DR, Adriaanse HP. Educational needs of stroke survivors and their family members, as perceived 
by themselves and by health professionals. Patient Educ Couns 1996;28:265-76.

10 Bahouth MN, Gottesman RF, Szanton SL. Primary 'dehydration' and acute stroke: a systematic research review. J Neurol 2018;265:2167-81.

11 Cortés-Vicente E, Guisado-Alonso D, Delgado-Mederos R, et al. Frequency, risk factors, and prognosis of dehydration in acute stroke. Front Neurol 2019;10:305.

12 Picetti D, Foster S, Pangle AK, et al. Hydration health literacy in the elderly. Nutr Healthy Aging 2017;4:227-37.

13 Tsai Y-H, Yang J-L, Lee I-N, et al. Effects of dehydration on brain perfusion and infarct core after acute middle cerebral artery occlusion in rats: evidence from high-field magnetic resonance imaging. Front Neurol 2018;9:786.

14 Rowat A, Graham C, Dennis M. Dehydration in hospital-admitted stroke patients: detection, frequency, and association. Stroke 2012;43:857-9.

15 Bowry R, Navalkele DD, Gonzales NR. Blood pressure management in stroke: five new things. Neurol Clin Pract 2014;4:419-26.

16 Appleton JP, Sprigg N, Bath PM. Blood pressure management in acute stroke. Stroke Vasc Neurol 2016;1:72-82.

17 Weyland A, Stephan H, Kazmaier S, et al. Flow velocity measurements as an index of cerebral blood flow. Validity of transcranial Doppler sonographic monitoring during cardiac surgery. Anesthesiology 1994;81:1401-10.

18 Sorond FA, Hollenberg NK, Panych LP, et al. Brain blood flow and velocity: correlations between magnetic resonance imaging and transcranial Doppler sonography. J Ultrasound Med 2010;29:1017-22.

19 Olavarría VV, Lavados PM, Muñoz-Venturelli P, et al. Flat-head positioning increases cerebral blood flow in anterior circulation acute ischemic stroke. A cluster randomized phase llb trial. Int J Stroke 2018;13:600-11.

20 Hunter AJ, Snodgrass SJ, Quain D, et al. HOBOE (Head-of-Bed optimization of elevation) study: association of higher angle with reduced cerebral blood flow velocity in acute ischemic stroke. Phys Ther 2011;91:1503-12.

21 Cumming TB, Thrift AG, Collier JM, et al. Very early mobilization after stroke fast-tracks return to walking: further results from the phase II AVERT randomized controlled trial. Stroke 2011;42:153-8.
22 Sundseth A, Thommessen B, Rønning OM. Outcome after mobilization within 24 hours of acute stroke: a randomized controlled trial. Stroke 2012;43:2389-94.

23 Portney LG, Watkins MP. Foundations of clinical research. 3rd edn. New Jersey: Pearson, 2009.

24 Davies NJ, Kinman G, Thomas RJ, et al. Information satisfaction in breast and prostate cancer patients: implications for quality of life. Psychooncology 2008;17:1048-52.

25 Pusic MV, Ching K, Yin HS, et al. Seven practical principles for improving patient education: evidence-based ideas from cognition science. Paediatr Child Health 2014;19:119-22.

26 Friedman AJ, Cosby R, Boyko S, et al. Effective teaching strategies and methods of delivery for patient education: a systematic review and practice guideline recommendations. J Cancer Educ 2011;26:12-21.

27 Cassidy JM, Cramer SC, Spontaneous. Spontaneous and Therapeutic-Induced mechanisms of functional recovery after stroke. Trans/ Stroke Res 2017;8:33-46.

28 Seners P, Turc G, Oppenheim C, et al. Incidence, causes and predictors of neurological deterioration occurring within $24 \mathrm{~h}$ following acute ischaemic stroke: a systematic review with pathophysiological implications. J Neurol Neurosurg Psychiatry 2015;86:87-94

29 Ogata T, Yasaka M, Wakugawa Y, et al. Predisposing factors for acute deterioration of minor ischemic stroke. J Neurol Sci 2009;287:147-50.

30 Hoffmann T, McKenna K, Worrall L, et al. Randomised trial of a computer-generated tailored written education package for patients following stroke. Age Ageing 2007;36:280-6.

31 Yew KS, Cheng E. Acute stroke diagnosis. Am Fam Physician 2009;80:33-40.

32 Magrabi F, Habli I, Sujan M, et al. Why is it so difficult to govern mobile apps in healthcare? BMJ Health Care Inform 2019;26:e100006.

33 Cupertino AP, Cartujano-Barrera F, Basile Colugnati FA, et al. Webbased decision-making tool for smoking cessation (Pare de fumar conosco) among patients with chronic conditions in Brazil : one-arm feasibility study. BMJ Health Care Inform 2020;27:e100063. 